\title{
Synthesis and Liquid Crystalline Properties of New Thermotropic Polyurethanes
}

\author{
Yanqing Lian, Mingqi LI, Jun Zhan, Qixiang Zhou, \\ and Deshan Liu ${ }^{\dagger}$ \\ Institute of Polymer Science and Engineering, Department of Chemical Engineering, \\ Tsinghua University, Beijing, 100084, People's Republic of China
}

(Received January 14, 1999)

\begin{abstract}
Mesogenic diol monomer, terephthaloyl dioxydibenzoic acid diol ester $(n=2,3,4,5,6)$, were prepared from $\omega$-hydroxyalkyl-4-hydroxybenzoate and terephthalyl chloride, using Schotten-Baumann Reaction. New liquid crystalline polyurethanes (LCPUs) were obtained by solution polymerization mesogenic diol monomers with 4,4'-diphenylmethane diisocyanate (MDI) and 2,4-tolylene diisocyanate (2,4-TDI). The monomer and polyurethanes were investigated by DSC, polarizing microscopy, wide-angle X-ray diffraction (WAXD), small-angle X-ray diffraction (SAXD) and high temperature X-ray diffraction. All LCPUs synthesized showed a nematic LC nature with wide temperature range.
\end{abstract}

KEY WORDS Polyurethane / Thermotropic Liquid Crystalline Polymer /

The synthesis of liquid crystalline (LC) main-chain polymers has been intensely investigated because of their theoretical properties and technological applications. ${ }^{1-3}$ In particular, a large variety of works has focused on thermotropic polyesters and polyamides. For polyurethanes, the polymer backbone becomes very rigid due to the formation of hydrogen bonds so that considerable investigation in this field were not made until last decade.

In 1981, Iimura and co-workers first reported thermotropic polyurethanes prepared by polyaddition of 3,3'-dimethyl-4,4'-biphenyldiyl diisocyanate with $\alpha, \omega$ alkanediols. ${ }^{4}$ Later, main-chain liquid crystalline polyurethanes (MLCPUs) with various molecular structures were synthesized. These polyurethanes can be subdivided into five groups by synthetic routes ${ }^{5,6}$ :

(1) MLCPU, prepared by reactions of diisocyanates with diols having mesomorphic groups as core units, ${ }^{7,8-27}$

(2) those prepared by reactions of diols with diisocyanates having mesomorphic groups as core units, ${ }^{4,28-35}$

(3) those prepared by condensation reactions of dichloroformates with diamines, ${ }^{36}$

(4) those prepared by melt condensation reactions of diisocyanates blocked with phenol with diols having biphenyl groups as core units, ${ }^{37-39}$

(5) those prepared by reaction of an aromatic carbamoyl dichloride with a mesogen-containing diol. ${ }^{40,41}$

This research investigates the synthesis and thermotropic properties of a new series of MLCPUs by reactions of diisocyanate monomers, i.e., 2,4-tolylene diisocyanate (2,4-TDI), 4,4-diphenylmethane diisocyanate (MDI), with mesogenic diol monomers, terephthaloyl dioxydibenzoic acid diol esters (3a-e) (Scheme 1). The polymers are prepared by solution polyaddition in $N, N$-dimethylformamide (DMF). The effects of the length of the alkylene spacers on thermal properties are discussed for both polyurethanes.

\footnotetext{
$\uparrow$ To whom correspondence should be addressed.
}

\section{EXPERIMENTAL}

\section{Materials}

Commercially available 2-chloroethanol, 1,3-propanediol, 1,4-butanediol, 1,5-pentanediol, 1,6-hexanediol, and 4-hydroxybenzoic acid were used without further purification. Commercially available MDI, 2,4-TDI, and terephthalyl chloride were distilled before use.

\section{Monomer Synthesis}

Mesogenic diol monomer, terephthaloyl dioxydibenzoic acid diol ester 3a-e, were synthesized according to the same general procedure outlined in Scheme 1. As a typical example, the synthesis of terephthaloyl dioxydibenzoic acid hexanediol ester (1e) is reported.

6-Chlorohexanol (1e). A solution of $45 \mathrm{~mL}(0.38 \mathrm{~mol})$ 1,6-hexanediol in $200 \mathrm{~mL}(2.03 \mathrm{~mol})$ hydrochloric acid was reacted under $90^{\circ} \mathrm{C}$ for $15 \mathrm{~h}$, using toluene to consecutively extract the product. The crude product was distilled under normal pressure to remove toluene and then distilled under vacuum pressure $\left(100-104^{\circ} \mathrm{C} / 9.3 \times\right.$ $10^{-4} \mathrm{MPa}$ ) to give $1 \mathrm{e}$ (yield $27.5 \%$ ).

1a was commercially available and $\mathbf{1 b}, \mathbf{1 c}$, and $\mathbf{1 d}$ were synthesized according to the similar procedure with yields ranging from $24 \%$ to $34 \%$.

6-Hydroxyhexyl-4-hydroxybenzoate (2e). 2e was prepared by a similar procedure given by Angeloniet al. ${ }^{26}$ A solution of 4-hydroxybenzoic acid $(0.258 \mathrm{~mol}, 35.6 \mathrm{~g})$, anhydrous potassium bicarbonate $(0.258 \mathrm{~mol}, 25.8 \mathrm{~g})$ and

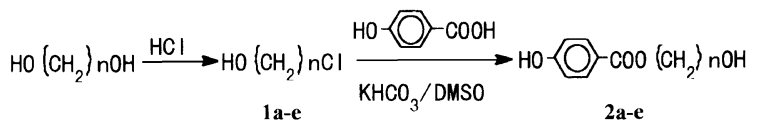

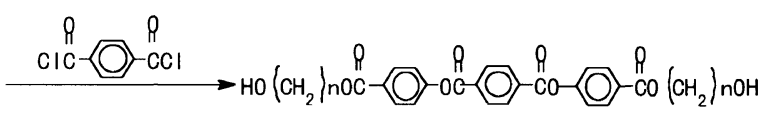

$$
\begin{aligned}
& \text { 3a-e } \\
& \text { 1a-3a: } n=2 ; \quad 1 b-3 b: n=3 ; \quad 1 c-3 c: n=4 ; \quad 1 d-3 d: n=5 ; \quad 1 e-3 e: n=6
\end{aligned}
$$


1e $(0.215 \mathrm{~mol}, 29.4 \mathrm{~g})$ in $120 \mathrm{~mL}$ of dry dimethylsulfoxide was stirred at $80^{\circ} \mathrm{C}$. After $5 \mathrm{~h}$, the mixture was poured into $700 \mathrm{~mL}$ cold water saturated with sodium chloride and kept at $5^{\circ} \mathrm{C}$ overnight. The crude product was filtered, washed with cold water and dried. The residue was recrystallized from chloroform to give $37.4 \mathrm{~g}$ (yield $73 \%$ ) of 1e: $\mathrm{mp} 100^{\circ} \mathrm{C}$.

${ }^{1} \mathrm{H}$ NMR (dimethyl sulfoxide (DMSO)- $d_{6}$ ): $\delta=10.35$ $(\mathrm{s},-\mathrm{Ar}-\mathrm{OH}, 1 \mathrm{H}), \delta=7.80,6.85(\mathrm{q},-\mathrm{Ar}-\mathrm{H}, 4 \mathrm{H}), \delta=4.40$ $(\mathrm{s},-\mathrm{OH}, 1 \mathrm{H}), \delta=4.20\left(\mathrm{t},-\mathrm{COOCH}_{2}-2 \mathrm{H}\right), \delta=3.40(\mathrm{t}$, $\left.-\mathrm{CH}_{2} \mathrm{OH}, 2 \mathrm{H}\right), \delta=1.90-1.20\left(\mathrm{~m},-\left(\mathrm{CH}_{2}\right)_{4}^{-}, 8 \mathrm{H}\right)$.

$$
\begin{array}{llll}
\mathrm{C}_{13} \mathrm{H}_{18} \mathrm{O}_{4}(238) & \text { Calcd } & \mathrm{C} 65.55 & \mathrm{H} 7.56 \\
& \text { Found } & \mathrm{C} 65.51 & \mathrm{H} 7.65
\end{array}
$$

Crude products $\mathbf{2 a}-\mathbf{d}$ were recrystallized from water $\left(\mathrm{mp}_{\mathrm{a}}: 142^{\circ} \mathrm{C}\right)$, chloroform $\left(\mathrm{mp}_{\mathrm{b}}: 99^{\circ} \mathrm{C}\right)$, chloroform $\left(\mathrm{mp}_{\mathrm{c}}\right.$ : $\left.92^{\circ} \mathrm{C}\right)$, and benzene $\left(\mathrm{mp}_{\mathrm{d}}: 110^{\circ} \mathrm{C}\right)$ respectively with yields ranging from $52 \%$ to $65 \%$.

Terephthaloyl Dioxydibenzoic Acid Hexanediol Ester (3e). 3e was prepared by condensation reaction of $2 \mathrm{~mol}$ of $2 \mathbf{e}$ with $1 \mathrm{~mol}$ of terephthaloyl chloride according to the Schotten-Baumann reaction. Into a $100 \mathrm{~mL}$ threenecked flask, equipped with a mechanical stirrer, thermometer and dropping funnel, were placed $9.52 \mathrm{~g}$ $(0.04 \mathrm{~mol}) 2 \mathrm{e}$ and a solution of $1.76 \mathrm{~g}(0.044 \mathrm{~mol})$ sodium hydroxide in $20 \mathrm{~mL}$ distilled water. After cooling the solution to $10^{\circ} \mathrm{C}, 4.06 \mathrm{~g}(0.02 \mathrm{~mol})$ terephthaloyl chloride dissolved in $36 \mathrm{~mL}$ acetone were added slowly to the stirred solution, which caused the product to precipitate from the solution. The reaction mixture was maintained at $10-15^{\circ} \mathrm{C}$ during the addition and allowed to rise to room-temperature. After being kept at this temperature for $2 \mathrm{~h}$, the precipitate was filtered and washed well with $1 \mathrm{wt} \%$ aqueous sodium hydroxide to remove the unreacted species and by-products. The residue was recrystallized two or three times from 2-butanone to give 3e (yield $65 \%$ ): $T_{\mathrm{m}}: 143^{\circ} \mathrm{C}, T_{\mathrm{i}}: 174^{\circ} \mathrm{C}$.

${ }^{1} \mathrm{H}$ NMR (DMSO- $\left.d_{6}\right): \delta=8.37$ (s, $\left.-\mathrm{Ar}-\mathrm{H}, 4 \mathrm{H}\right)$, $\delta=8.12(\mathrm{~d},-\mathrm{Ar}-\mathrm{H}, 4 \mathrm{H}), \delta=7.52(\mathrm{~d},-\mathrm{Ar}-\mathrm{H}, 4 \mathrm{H}), \delta=4.30$ $\left(\mathrm{t},-\mathrm{COOCH}_{2}-, 2 \mathrm{H}\right), \delta=3.40\left(\mathrm{t},-\mathrm{CH}_{2} \mathrm{OH}, 2 \mathrm{H}\right)$, $\delta=1.90-1.30\left(\mathrm{~m},-\left(\mathrm{CH}_{2}\right)_{4}^{-}, 8 \mathrm{H}\right)$.

$$
\begin{array}{llll}
\mathrm{C}_{34} \mathrm{H}_{38} \mathrm{O}_{10}(606) & \text { Calcd } & \mathrm{C} 67.33 & \text { H } 6.27 \\
& \text { Found } & \mathrm{C} 67.30 & \text { H } 6.29
\end{array}
$$

2-Butanone was also used as recrystalline solvent to 3a $\left(T_{\mathrm{m}}: 213^{\circ} \mathrm{C}, T_{\mathrm{i}}: 265^{\circ} \mathrm{C}\right), 3 \mathbf{b}\left(T_{\mathrm{m}}: 177^{\circ} \mathrm{C}, T_{\mathrm{i}}: 208^{\circ} \mathrm{C}\right), 3 \mathbf{c}$ $\left(T_{\mathrm{m}}: 167^{\circ} \mathrm{C}, T_{\mathrm{i}}: 211^{\circ} \mathrm{C}\right)$, and $3 \mathrm{~d}\left(T_{\mathrm{m}}: 156^{\circ} \mathrm{C}, T_{\mathrm{i}}: 188^{\circ} \mathrm{C}\right)$ with yields ranging from $45 \%$ to $65 \%$.

\section{Polymer Synthesis}

All polymerizations were carried out under dry nitrogen and highly purified and dried $N, N$-dimethylacetamide (DMAc) was used as solvent. Into a $100 \mathrm{~mL}$ three-necked flask equipped with a reflux condenser with a drying tube, equimolar quantity of diisocyanate was added dropwise a solution of $\mathbf{3 a}-\mathbf{e}$ and catalyst dibutyl tin dilaurate in DMAc. The reaction mixture was maintained at $60^{\circ} \mathrm{C}$ for $2 \mathrm{~h}$ after the addition and allowed to rise to $70^{\circ} \mathrm{C}$ for $4 \mathrm{~h}$. At the end of the reaction, the solution was poured into methanol to precipitate the polymer in the form of a white material. This polymer was washed with methanol, and subsequently dried under vacuum at $60^{\circ} \mathrm{C}$.

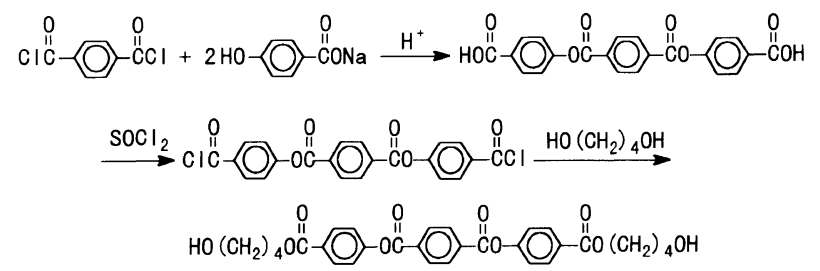

Scheme 2.

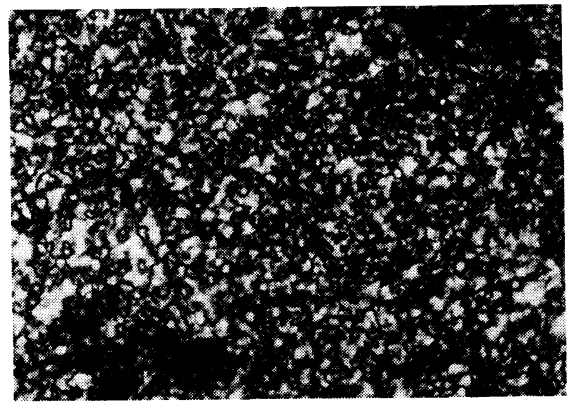

Figure 1. Optical microphotography $(200 \times)$ of $3 d$ at $170^{\circ} \mathrm{C}$.

Table I. LC phase transition temperature of mesogenic diol 3a e by DSC

\begin{tabular}{cccc}
\hline & \multicolumn{2}{c}{ Transition temperature $/{ }^{\circ} \mathrm{C}$} & \\
\cline { 2 - 3 } Formula & $T_{\mathrm{m}}$ & $\Delta T /{ }^{\circ} \mathrm{C}$ \\
& 213 & $T_{\mathrm{i}}$ & \\
\hline 3a & 177 & 265 & 52 \\
3b & 167 & 208 & 31 \\
3c & 156 & 211 & 44 \\
3d & 143 & 188 & 32 \\
3e & & 174 & 31 \\
\hline
\end{tabular}

\section{Measurements}

${ }^{1} \mathrm{H}$ NMR spectra were measured in DMSO- $d_{6}$ by a UNITY-200 spectrometer. DSC and TGA data were obtained on a General 4.1 Dupont 2100 system at a heating rate of $10^{\circ} \mathrm{Cmin}^{-1}$. Thermal properties in connection with the morphological observation were investigated by Olympus BH-2 microscope equipped with a Leitz heated stage. X-Ray diffraction patterns (SAXD or WAXD) were obtained with a diffractometer, type Ricon D/Max-RB with $\mathrm{Cu}-K_{\alpha}$. High temperature X-ray diffraction measurements were performed using the Rigaku D£Max 200 diffractometer.

\section{RESULTS AND DISCUSSION}

\section{Synthesis}

General reaction routes for the series of mesogenic diol monomer, terephthaloyl dioxydibenzoic acid diol ester 3a-e are shown in Scheme 1. Compared with another equivocal synthetic method (Scheme 2), ${ }^{42} \omega$ hydroxyalkyl 4-hydroxybenzoate $\mathbf{2 a}$-e are more likely to inhibit the polymerization because of the different natures of the aromatic hydroxyl and aliphatic hydroxyl.

According to the Schotten-Baumann reaction, mesogenic diol monomer $3 \mathbf{a}$ - e can be obtained with typical nematic features. Figure 1 shows a polarizing optical microphotograph of diol 3d. Similar textures were observed in other samples.

From the data in Table I increase in spacer length 
results in lower phase transition temperature $T_{\mathrm{m}}$ and $T_{\mathrm{i}}$.

General reaction routes of polymerization in this study are shown in Scheme 3. In the presence of dibutyl tin dilaurate as catalyst, all novel thermotropic liquid crystalline polyurethane was synthesized by polyaddition of mesogenic diol 3a-e with MDI or 2,4-TDI. The LCPUs showed good solubilities in aprotic organic solvents, such as DMAc, $N$-methyl-2-pyrrolidone (NMP), and DMF.

\section{Properties of Liquid Crystalline Polyurethanes}

Inherent viscosities in DMF and phase transition of all LCPUs synthesized are shown in Table II and Figures $2-4$. The results were in accordance with the polarizing optical microscope observation. DSC traces of LCPU1 and LCPU2 exhibited two or more endothermic peaks. TGA of 3d-MDI showed the isotropization temperature $\left(T_{\mathrm{i}}\right)$ close to the degradation temperature $\left(T_{\mathrm{d}}\right)$.

Figure 5 shows typical polarizing optical microphoto-

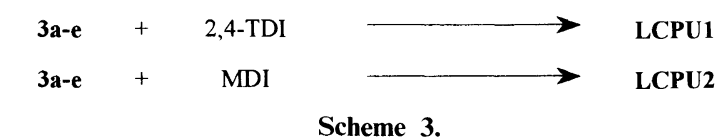

Table II. $\eta_{\text {inh }}$ and LC phase transitions by DSC of polyurethanes

\begin{tabular}{|c|c|c|c|c|}
\hline \multirow{2}{*}{ Formula } & \multirow{2}{*}{$\eta_{\mathrm{inh}} / \mathrm{dlg}^{-1}$} & \multicolumn{2}{|c|}{ Transition temperature $/{ }^{\circ} \mathrm{C}$} & \multirow{2}{*}{$\Delta T /{ }^{\circ} \mathrm{C}$} \\
\hline & & $T_{\mathrm{m}}$ & $T_{\mathrm{i}}$ & \\
\hline 3a-2,4-TDI & 0.29 & 132 & 274 & 142 \\
\hline 3d-2,4-TDI & 0.10 & 92 & 269 & 177 \\
\hline 3a-MDI & 0.11 & 196 & $314^{\mathrm{a}}$ & 118 \\
\hline 3b-MDI & 0.13 & 191 & $333^{\mathrm{a}}$ & 142 \\
\hline 3c-MDI & 0.11 & 171 & $333^{\mathrm{a}}$ & 162 \\
\hline 3d-MDI & 0.13 & 156 & $332^{\mathrm{a}}$ & $176^{\circ}$ \\
\hline 3e-MDI & 0.10 & 147 & $331^{\mathrm{a}}$ & 184 \\
\hline
\end{tabular}

${ }^{\text {a }} T_{\mathrm{i}} \approx T_{\mathrm{d}}$.

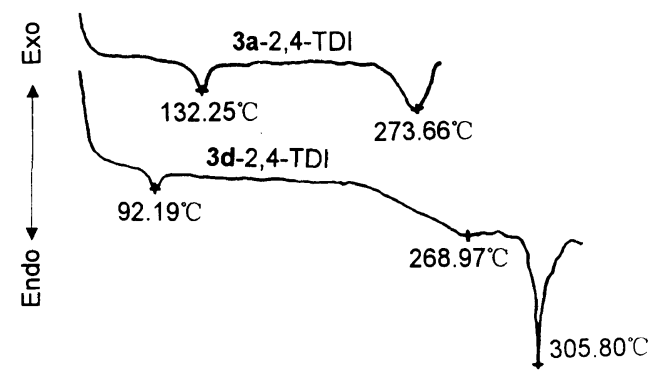

Figure 2. DSC curves of LCPU1.

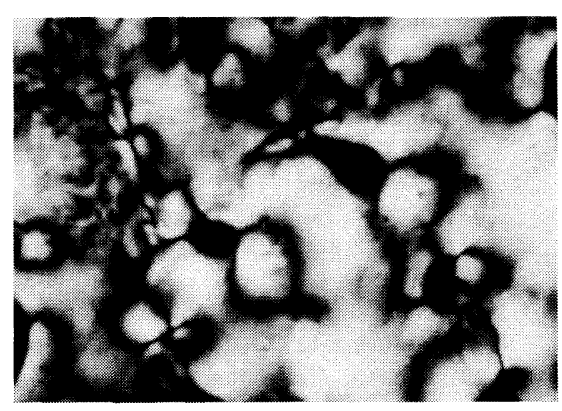

(a) graph of LCPU1 and LCPU2. Similar textures were observed for other samples.

Results of wide-angle X-ray diffraction (WAXD)

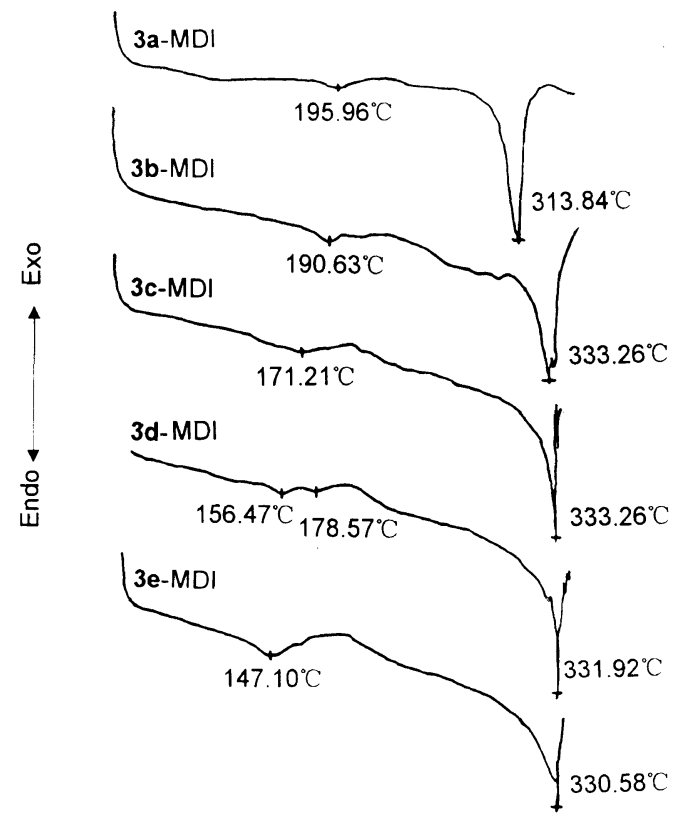

Figure 3. DSC curves of LCPU2.

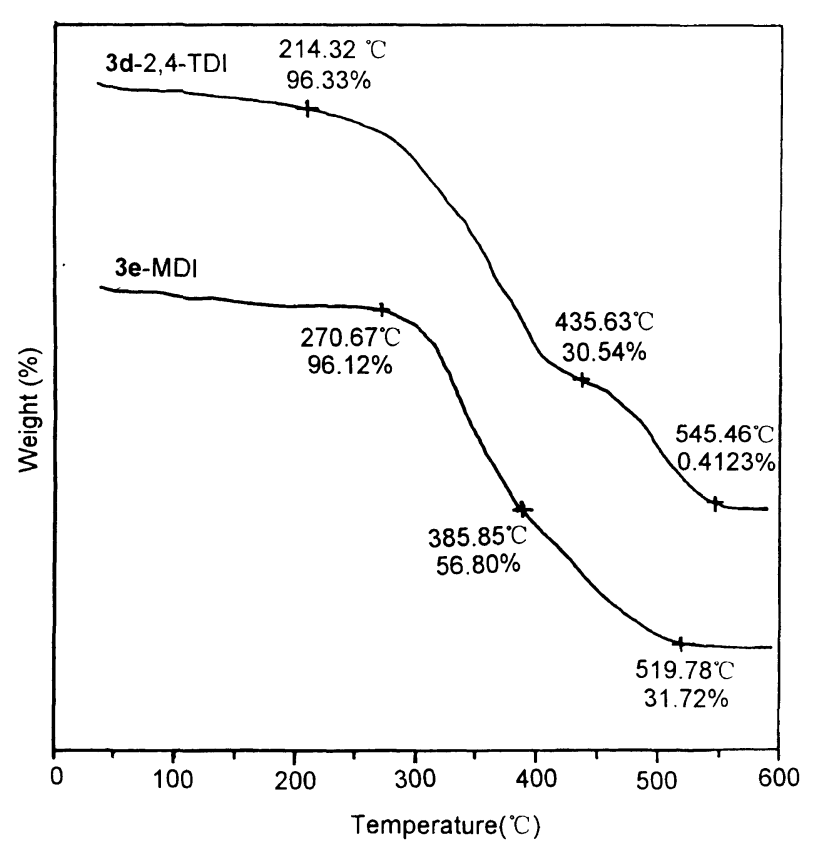

Figure 4. TGA curves of polyurethanes.

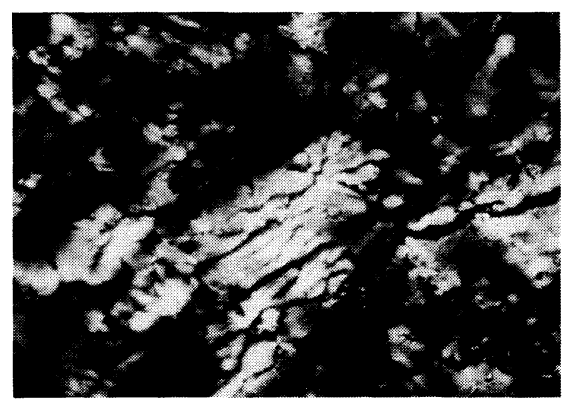

(b)

Figure 5. Optical microphotography $(400 \times)$ of LCPU1 and LCPU2. (a), 3a-2,4-TDI at $180^{\circ} \mathrm{C}$; (b), 3e-MDI at $180^{\circ} \mathrm{C}$. 


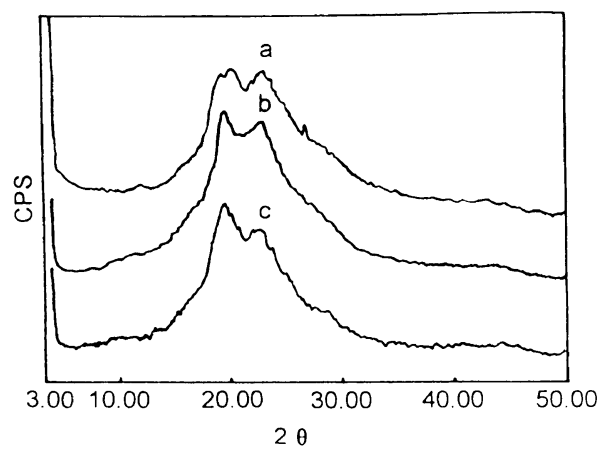

Figure 6. WAXD patterns for LCPU1 at room temperature. a, 3d-2,4-TDI quenching in liquid- $\mathrm{N}_{2}$ from $200^{\circ} \mathrm{C}$; b, 3a-2,4-TDI; c, 3d-2,4-TDI

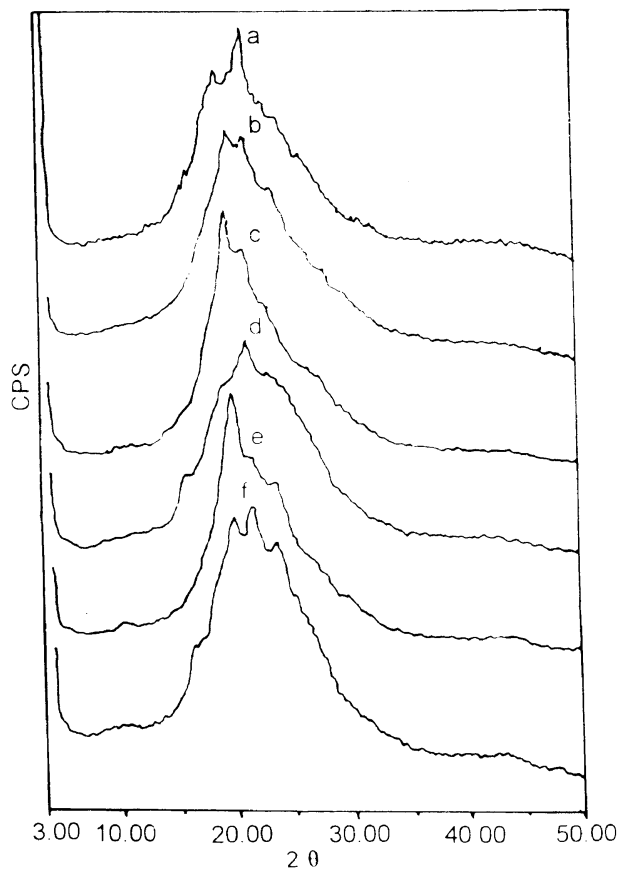

Figure 7. WAXD patterns for LCPU2 at room temperature. a, 3e-MDI quenching in liquid- $\mathrm{N}_{2}$ from $200^{\circ} \mathrm{C}$; b, 3a-MDI; c, 3b-MDI; d, 3c-MDI; e, 3d-MDI; f: 3e-MDI.

analysis of both PUs conducted at room temperature are shown in Figures 6 and 7. WAXD measurements showed dispersing peaks at $2 \theta \approx 20^{\circ}$ as well as some crystalline peaks due to the strong tendency of the urethane groups to form $\mathrm{H}$-bonds. Quenching from the mesomorphic temperature in liquid $\mathrm{N}_{2}$ did not cause significant effects on WAXD profiles. There was a wide peak at $2 \theta \approx 20^{\circ}$, but few sharp peaks in the X-ray diffraction pattern of 3d-2,4-TDI at melting state $\left(160^{\circ} \mathrm{C}\right)$, which had longer soft spaces(Figure 8). Figure 9 represents the SAXD patterns at room temperature for LCPUs of 3d-2,4-TDI and 3e-MDI quenching in liquid $\mathrm{N}_{2}$ from mesomorphic temperature. The blank small-angle region indicated no long-distance order sequence for both LCPUs. With shorter flexible space, similar results were obtained for other LCPUs. It is obvious that all the samples are not smectic. They are nematic.

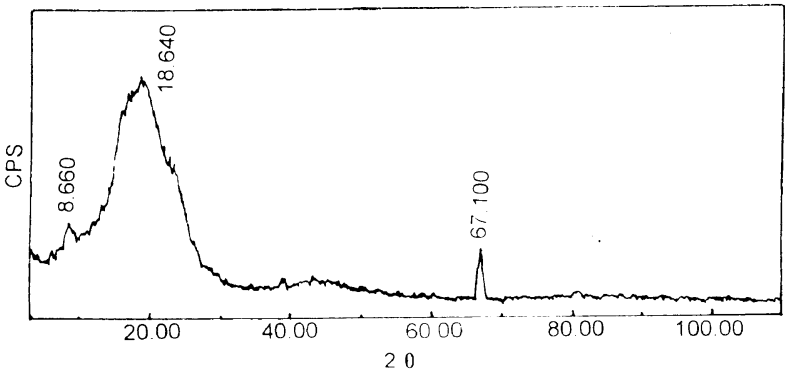

Figure 8. X-ray diffraction pattern of 3d-2,4-TDI at $160^{\circ} \mathrm{C}$.

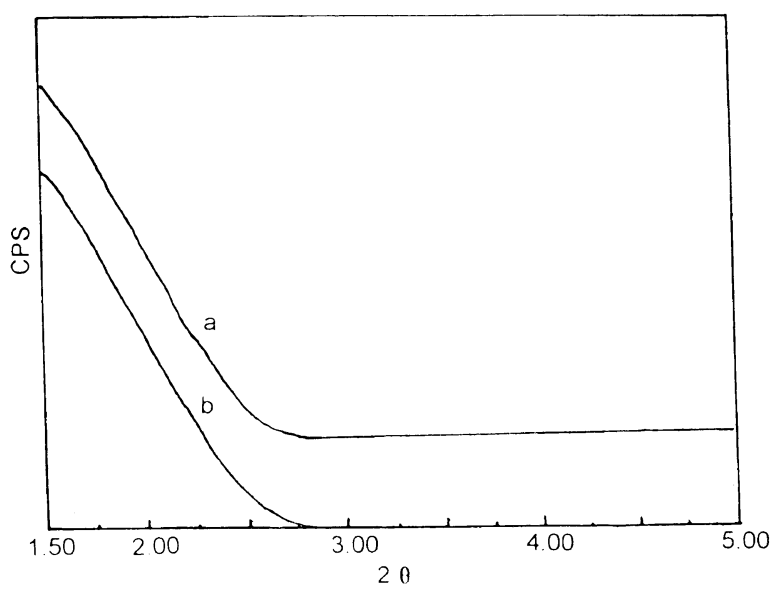

Figure 9. SAXD patterns for polyurethanes at room temperature. a, 3d-2,4-TDI quenching in liquid- $\mathrm{N}_{2}$ from $200^{\circ} \mathrm{C}$; b: 3e-MDI quenching in liquid- $\mathrm{N}_{2}$ from $200^{\circ} \mathrm{C}$

\section{CONCLUSIONS}

A series of nematic liquid crystalline diol monomers $(3 \mathbf{a}-\mathbf{e})$ were synthesized by a new method. Increase in spacer length results in lower phase transition temperature $T_{\mathrm{m}}$ and $T_{\mathrm{i}}$.

Novel liquid crystalline LCPU1 and LCPU2 were prepared through solution polymerization of $(\mathbf{3 a}-\mathbf{e})$ with MDI or 2,4-TDI respectively. They exhibit nematic LC textures. The $T_{\mathrm{i}}$ of polyurethanes based on MDI are close to the $T_{\mathrm{d}}$. The phase transition temperatures of polyurethanes based on MDI are higher than those based on 2,4-TDI.

\section{REFERENCES}

1. H. Finkelmann, H. Ringsdorf, and J. H. Wendorff, Makromol. Chem., 179, 273 (1978).

2. A. Blumstein, "Liquid Crystalline Polymers," C. B. Mcardle, Ed., Blackie \& Sons Ltd., Glasgow, Scotland, 1989.

3. International Conference on Liquid Crystal Polymers, Bordeaux, France, July 20-24, 1987.

4. K. Iimura, N. Koide, H. Tanabe, and M. Takeda, Makromol. Chem., 182, 2569 (1981).

5. M. Tanaka and T. Nakaya, Advanced in Urethane Science and Technology, 12, 1 (1993).

6. M. Tanaka and T. Nakaya, International Progress in Urethanes, 6, 62 (1993).

7. P. J. Stenhouse, E. M. Valles, S. W. Kantor, and W. J. MacKnight, Mocromolecules, 22, 1467 (1989).

8. M. Tanaka, Makromol. Chem., 187, 2345 (1986).

9. M. Tanaka and T. Nakaya, J. Macromol. Sci.,-Chem., A24, 777 (1987).

10. S. K. Pollack, D. Y. Shen, S. L. Hsu, Q. Wang, H. D. Stidham, 
Mocromolecules, 22, 551 (1989).

11. D. Y. Shen and S. K. Pollack, Mocromolecules, 22, 2564 (1989).

12. G. Smyth, E. M. Valles,S. K. Pollack, J. Grebowicz, P. J. Stenhouse, S. L. Hsu, and W. J. MacKnight, Mocromolecules, 23, 3389 (1990).

13. S. K. Pollack, G. Smyth, F. Papadimitrakopoulos, P. J. Stenhouse, S. L. Hsu, and W. J. MacKnight, Mocromolecules, 25, 2381 (1992).

14. S. K. Pollack, G. Smyth, Polym. Prepr., Am. Chem. Soc., Div. Polym. Chem., 30, 517 (1989).

15. H. Kothandaraman and A. Sultannasar, J. Macromol. Sci., Pure Chem., A31, 339 (1994).

16. F. Papadimitrakopoulos, S. L. Hsu, and W. J. MacKnight, Mocromolecules, 25, 4671 (1992).

17. F. Papadimitrakopoulos, E. Sawa, and W. J. MacKnight, Mocromolecules, 25, 4682 (1992).

18. J. B. Lee, T. Kato, T. Yoshida, and T. Uryu, Mocromolecules, 26, 4989 (1993)

19. X. Jia, X. He, and X. Yu, J. Applied Polym. Sci., 62, 465 (1996)

20. M. Furukawa, Y. Oda, and H. Higashi, IRC ' 95 , Kobe, Japan, October 23-27, 1995.

21. Y. Onouchi, S. Inagaki, H. Okamoto, and J. Furukawa, IRC '95, Kobe, Japan, October, 23-27, 1995.

22. J. C. Tang and T. C. Chang, Eur. Polym. J., 30, 1059 (1994).

23. K. Sugiyama, K. Shiraishi, and K. Kato, Polym. J., 25, 103 (1993).

24. M. T. Chidade and J. C. M. Boadado, Liquid Crystals, 13, 295 (1993)

25. H. R. Haridas and G. Radhahrishnan, J. Polym. Sci., Part A, Polym. Chem., 33, 901 (1995).

26. A. S. Angeloni, M. Laus, E. Chiellini, G. Galli, and O.
Francescangeli, Eur. Polym. J., 31, 253 (1995).

27. E. Chiellini, G. Galli, and S. Trusendi, Mol. Cryst. Liq. Cryst. 243, 135 (1994)

28. W. Mormann and M. Brahm, Makromol. Chem., 190, 631 (1989).

29. W. Mormann, Polym. Prepr., Am. Chem. Soc. Div. Polym. Chem., 30, 291 (1989).

30. W. Mormann, S. Benadda, and M. Brahm, Makromol. Chem Phys., 196, 543 (1995).

31. W. Mormann, M. Brahm, and S. Benadda, "Integration of Fudamental Polymer Science and Technology," Vol. 5, Elsevier Applied Science, London, 1991, p 219.

32. W. Mormann and M. Brahm, Polymer, 34, 187 (1993).

33. W. Mormann and A. Baharifur, Polym. Bull., 24, 413 (1990).

34. W. Mormann and M. Brahm, Mocromolecules. 24, 1096 (1991).

35. W. Mormann and E. Hohn, Makromol. Chem., 190, 1919 (1989).

36. M. Sato, F. Komatsu, N, Takeno, and K. Mukaida, Makromol. Chem., Rapid Commun., 12, 167 (1991).

37. H. R. Kricheldorf and J. Awe, Makromol. Chem., 190, 2597 (1989)

38. H. R. Kricheldorf and J. Awe, Makromol. Chem., 190, 2579 (1989).

39. H. R. Kricheldorf and J. Awe, Makromol. Chem. Rapid Commun., 9, 681 (1988)

40. F. Papadimitrakopoulos, S. W. Kantor, and W. J. MacKnight, Polym. Prepr., Am. Chem. Soc., Div. Polym. Chem., 31, 486 (1990).

41. S. Trusendi, Thesis, University of Pisa, 1992.

42. X. Han, B. Zhao, Y. Ni, E. Zhou, and X. Jing, Functional Polym. J., 7, 405 (1994). 